\title{
Microbiology Specimen Result Standard Unit
}

National Cancer Institute

\section{Source}

National Cancer Institute. Microbiology Specimen Result Standard Unit. NCI Thesaurus.

Code C87916.

The standard unit of measure for microbiology specimen results. 